\title{
Lenguaje, narración y cultura de la vida: la realidad inmanente de lo humano en la fenomenología de Michel Henry
}

\author{
Language, narration and culture of life: \\ the immanent reality of the human in the \\ phenomenology of Michel Henry ${ }^{l}$
}

Cesare del Mastro Puccio ${ }^{2}$

Universidad del Pacífico, Perú

Recepción: 15 de junio del 2020

Evaluación: 07 de julio del 2020

Aceptación: 20 de julio de 2020

1 Este artículo presenta algunos resultados del proyecto de investigación titulado "Lengua fenomenológica y escritura novelesca: investigaciones a partir de Michel Henry", iniciado en el Fondo Michel del Instituto Superior de Filosofía de la Universidad Católica de Lovaina - UCL, con el apoyo del Fondo Nacional de la Investigación Científica Belga - FNRS, y concluido en el Centro de Investigación de la Universidad del Pacífico en Lima.

2 Doctor en Filosofía, Magíster en Estudios ibéricos e iberoamericanos y Licenciado en Lingüística y Literatura con mención en Literatura hispánica de la Université Louvain-la Neuve, la Université catholique de Louvain y la Pontificia Universidad Católica del Perú, respectivamente.

Correo electrónico: c.delmastropuccio@up.edu.pe 


\title{
Resumen
}

A partir de los conceptos de "cultura" y "unidad ontológica de lo humano" en la fenomenología de la vida de Michel Henry, se afirma en este artículo la identidad entre el saber de la vida auto-afectiva y dos de los rasgos distintivos del viviente humano: la palabra y la narración. Abordada desde un lenguaje de la vida anterior a toda configuración lingüística y narrativa, la exposición a las palabras no se inscribe en el aparecer del mundo designado por ellas, sino en la realidad originaria del sentirse inmanente de la vida en ellas. Si bien todo lenguaje proviene del poder y del deseo de la vida subjetiva de experimentarse a sí misma en cada gesto del cuerpo, el hablar cotidiano y la creación literaria acrecientan de manera particularmente intensa dicha capacidad y dicho deseo. En efecto, lejos de representar la vida, la "narración del pathos" realiza la figuración inmediata del afecto y de la fuerza. Así, este trabajo pretende mostrar la novedad de la teoría henriana de los lenguajes del afecto respecto, por un lado, al debate en torno al humanismo y el post-humanismo y, por otro lado, al vínculo entre fenomenología y hermenéutica.

Palabras clave: Michel Henry, Paul Ricoeur, fenomenología, hermenéutica, humanismo.

\begin{abstract}
Based on the concepts of "culture" and "ontological unity of the human" in the phenomenology of life of Michel Henry, it is pointed out in this article the identity between the knowledge of self-affective life and two of the distinctive features of living human: the word and the narration. Approached from a language of life prior to any linguistic and narrative configuration, the exposure to words is not inscribed in the appearance of the world designated by them but in the original reality of feeling immanent in life in them. Although all language comes from the power and desire of the subjective life to experience itself in every gesture of the body, daily speech and literary creation increase in a particularly intense way this capacity and said desire. Indeed, far from representing life, the "narration of the pathos" realizes the immediate figuration of affect and force. Thus, this work aims to show the novelty of the Henrian theory of the languages of affect regarding, on the one hand, the debate around humanism and post-humanism and, on the other hand, the link between phenomenology and hermeneutics.
\end{abstract}

Keywords: Michel Henry, Paul Ricoeur, phenomenology, hermeneutics, humanism. 
En su libro de 1987, La barbarie, el fenomenólogo francés Michel Henry rechaza la reducción de la llamada crisis de la cultura a un simple momento en el que, como ha ocurrido siempre en la historia, tras una etapa de expansión viene un periodo de declive. Lo que acontece en nuestro tiempo es, por el contrario, "lo nunca visto". En efecto, a diferencia de los otros momentos de declive en los que "un nuevo despliegue tiene lugar, llevando más lejos el desarrollo de la vida" (Henry, 1996, pp. 15-16), a lo que nos enfrentamos hoy es a la destrucción misma de la vida. Ocurre que mientras que en otros periodos de la historia "era la totalidad de los valores que constituyen la humanidad los que se expandían a la vez" (Henry, 1996, pp. 15-16), la preeminencia del conocimiento objetivo y eficaz del que somos herederos desde la Modernidad ha desvinculado progresivamente el saber técnico de esa totalidad de valores; grave hundimiento que cuestiona nuestra existencia porque "es la misma vida la que es herida, son todos sus valores los que se tambalean; no solamente la estética, también la ética, lo sagrado -y con ellos la posibilidad de vivir cada día" (Henry, 1996, pp. 15-16).

"Lo nunca visto" es la ausencia radical de una perspectiva de conjunto sobre la existencia humana y su sentido. Los valores del arte, la ética y la religión se encuentran reducidos a la esfera de lo individual o a la mera decoración de lo que "realmente cuenta", es decir, de lo que es objetivo y útil. Henry denuncia la destrucción de la vida provocada por la ideología cientificista y técnica, ya que la praxis humana es amenazada en su constitución misma cada vez que la vida es olvidada en las estructuras de la cultura, del arte y de la educación. En efecto, vivir sin arte y sin memoria supone negar las expresiones más inmediatas de la realidad subjetiva y afectiva de la vida, la cual es substituida por una serie de abstracciones artificiales propuestas como el único saber válido. La barbarie denunciada por él consiste, pues, en un proceso de inversión de la lógica de crecimiento de la vida porque la primacía del saber objetivo impide que la afectividad y la sensibilidad proliferen en su deseo de experimentarse y de compartirse.

¿Cómo está involucrado el humanismo en esta barbarie; en qué medida este podría haber contribuido a la destrucción de la vida? Si la ontología de Michel Henry implica una filosofía del hombre, ¿cómo repensar lo humano en la realidad de la vida, en el ámbito de lo invisible, más acá de los rasgos de la humanitas, definidos por los diferentes humanismos a los que la historia de Occidente ha dado lugar? La primera parte de este artículo intenta responder a esta primera pregunta, mientras que los apartados segundo y 
tercero abordan la siguiente cuestión: ¿este enraizamiento inmanente de la humanitas en la vida subjetiva radical implica una redefinición de dos de los rasgos distintivos del viviente humano, a saber, el uso del lenguaje que hace de él un homo loquens, y la elaboración de relatos que permiten describirlo como homo narrans?

\section{De la dualidad humanista a la unidad ontológica de lo humano}

En la medida en que responde a una problemática ontológica radical, la filosofía del hombre de Henry se distancia del humanismo que define al ser humano a partir de rasgos exteriores, provenientes de la naturaleza o del pensamiento entendido como representación del mundo. En efecto, el problema radica en que dicho humanismo remite a un saber sobre el mundo que está ya siempre desarraigado del ámbito original del viviente humano, es decir, de la plenitud de la realidad en la inmanencia de su ser: esta vida subjetiva de naturaleza afectiva en la que él se experimenta a sí mismo de manera inmediata, "este ser esencialmente subjetivo y afectivo que marca con un índice de sufrimiento y de alegría todo lo que hace y todo lo que piensa" (DufourKowalska, 1996, p. 144) ${ }^{3}$. El saber humanista, que atribuye al ser humano los rasgos propios del homo loquens y del homo narrans no es, pues, el saber de la vida, sino el producto de definiciones elaboradas en el marco de una escuela. Construidas desde el exterior, dichas definiciones operan "fuera de la vida", según la estructura dual sujeto-mundo que pone al homo loquens delante de situaciones que él es capaz de representar a través de diferentes sistemas de signos. El ser humano observa luego satisfecho estos escenarios construidos por él; sin embargo, estos lo reafirman en una humanitas que no es ya fiel a lo real en su unicidad interna -aparecer invisible de la vida subjetiva en su pura inmanencia-, sino que proviene de una dualidad trascendente alienante -aparecer visible del mundo ante el sujeto.

La estructura dual en virtud de la cual se asocian el mundo-por-conocer y el sujeto-que-conoce, atraviesa todos los proyectos humanistas, tanto los que reivindican la trascendencia simbólico-axiológica del ser humano cuanto aquellos que se sitúan en el campo de su trascendencia técnico-científica. Así, por ejemplo, la orientación filológica del humanismo clásico estaba

\footnotetext{
Salvo que se indique lo contrario, todas las citas tomadas de obras escritas originalmente en francés han sido traducidas por el autor de este artículo.
} 
fundada en una antropología del lenguaje: el hombre habla y escribe porque es heredero de una tradición conformada por textos cuyo conocimiento lo distingue del resto de los seres vivos. El humanismo letrado confía en el poder de las propuestas de sentido del pasado para "domesticarnos": solo quien sabe apropiarse de las grandes obras del pensamiento y del arte de otros siglos se despoja de su "animalidad". Por su parte, el humanismo moderno subraya la condición de homo faber. El ser humano es valorado por su fuerza de trabajo, sumido en los instrumentos de la ciencia y la producción que conducen al progreso. El laboratorio y la fábrica se convierten en las nuevas bibliotecas; en ellas el ser humano traduce el mundo en lenguaje matemático y en artefacto, y se redime así de su "bestialidad". Si la estructura dual propia del humanismo clásico colocaba al homo loquens ante el objeto de su "intencionalidad filológica", la dualidad del humanismo moderno sitúa ora a la res cogitans ante la realidad visible que ella transforma en conocimiento, ora al homo faber frente a la realidad que él convierte en objeto manipulable y en producto de consumo. Todo rasgo distintivo del ser humano está fundado en esta dualidad humanista.

Incluso el discurso actual en torno al post-humanismo responde a esta estructura dual sujeto-objeto. Convertidos en los nuevos "domesticadores", sus representantes expulsan del parque humano al "club de lectores de obras antiguas", pero lo hacen a través de nuevos lenguajes en los que el sujeto sigue frente a la cara visible del mundo que él intenta transformar por medio de la convergencia de los avances de la tecnología, la biología y las ciencias cognitivas. Esta propuesta nos presenta nuevamente una definición de la especie humana "desde fuera", desde lo que el ser humano aún no es, pero podría llegar a ser: mientras que en el pasado el hombre produjo la técnica, hoy la técnica produce al ser humano y permite imaginarlo, en su constitución biológica misma, cualitativamente mejor. El post-humanismo prolonga el proyecto humanista de domesticación que pretende haber superado. En efecto, si el humanismo clásico definía al homo loquens por su relación con las letras del pasado, el post-humanismo imagina a la especie biológica humana mejorada gracias a la convergencia de los lenguajes de la biología y la técnica (Sloterdijk, 2000).

¿Es posible describir de otro modo lo humano en su posibilidad misma de experimentarse, por ejemplo, como este humano que habla y narra; desde un lenguaje de la vida anterior a todo esfuerzo de definición externa; desde una irrupción de lo humano en su realidad inmanente siempre afectiva, en 
su unidad original anterior a cualquier exigencia de "domesticación”, en un espacio de inmediatez invisible en el que nada aparece y nada se ofrece al conocimiento - ni el lenguaje de los textos del pasado ni el innovador de la tecnología- y en el que, sin embargo, el lenguaje y los relatos son este resonar de la vida en mí, esta reconducción por ellos hacia mí mismo, hacia mi poder de sentir, hacia la capacidad de experimentarme como esta subjetividad radical que habla y narra? En la medida en que supera el esquema dual del humanismo, la unidad ontológica de la vida auto-afectiva henriana nos permite acercarnos al hablar y al narrar humanos de otro modo.

Para ello es necesario describir toda cultura como una cultura de la vida, en virtud de la cual lo humano se experimenta a sí mismo en su inmediatez y en su unidad antes de cualquier definición del hombre en clave cultural-libresca, científico-económica o biológico-técnica. Esto exige, a su vez, asumir la prioridad del aparecer de la vida sobre el aparecer del mundo, lo que nos remite a una de las experiencias fundamentales de Michel Henry. En 1943, el filósofo se compromete en la Resistencia y experimenta la vida de la clandestinidad:

La experiencia de la Resistencia tuvo una profunda influencia en mi concepción de la vida. (...) Durante todo este periodo, se tenía que disimular lo que uno pensaba e incluso lo que uno hacía. Gracias a esta hipocresía permanente, la esencia de la vida verdadera me era revelada: ella es invisible. En los peores momentos, cuando el mundo se volvía atroz, yo lo experimentaba en mí como un secreto que debía proteger y que me protegía. Una manifestación más profunda y más antigua que la del mundo determinaba nuestra condición de seres humanos (...) Comprendí desde ese momento que la salvación del individuo no puede venirle del mundo (Henry, 2007, pp. 13-14).

Desde sus primeras obras (1963 y 1965), Henry describe esta duplicidad del aparecer en la que se enfrentan la exterioridad de lo visible y la interioridad de lo invisible. Por un lado, el aparecer del mundo corresponde a la trascendencia que permite a una conciencia salir de ella misma para ser "conciencia de algo", un "algo" que se encuentra fuera de ella, una realidad exterior que se ofrece a la vista y al conocimiento que se pretende objetivo. Este terreno de lo visible corresponde al ámbito de la exterioridad en el que se distinguen lo que aparece, aquel ante quien algo aparece y el acto mismo de aparecer. Por otro lado, el aparecer de la vida adviene en la inmanencia que remite al individuo a su propio sentir-se y experimentar-se. No hay aquí, entonces, separación entre lo que aparece y aquel ante quien algo aparece, pues no hay 
nada que aparezca fuera del viviente. Se trata del ámbito de la interioridad en el que se da el aparecer mismo de la vida en su invisibilidad, en un "espacio" de inmediatez interior, en el acto mismo de aparecer entendido como el poder de experimentarse según diversas tonalidades afectivas.

A partir de una crítica radical de las filosofías que confinan la fenomenalidad al horizonte de la visibilidad de "un mundo", Henry se distancia de todo pensamiento que remite al hombre directamente al mundo, olvidando el vínculo con la vida misma, vínculo que precede, funda y genera el lazo con el mundo. El poder del cuerpo que percibe es, antes que un poder intencional ("conciencia de algo"), un poder patético, es decir, consentimiento interior a sentirse afectado, a sufrir-se en el deseo de experimentar-se como subjetividad absoluta. Todo aparecer del mundo es posible gracias a este fondo de subjetividad $\mathrm{y}$, a su vez, toda percepción del mundo reconduce a este espacio invisible en el que el cuerpo viviente está en una postura de unidad y de coincidencia consigo mismo, con su poder de ser afectado al afectar-se: "Es, en suma, el inmenso proyecto de una fenomenología de la afectividad en la que ésta no es concebida como un simple contenido de experiencia, sino como la condición interior y primera de toda experiencia posible" (Leclercq, 2010, p. 15).

Este proyecto conduce al filósofo francés a considerar que toda cultura se basa en un saber distinto al de la ciencia y al de la conciencia: "Este saber es precisamente el de la vida, la cual, según nosotros hemos dado a entender, constituye por esencia tal saber, al ser ella el hecho mismo de experimentarse a sí misma en cada punto de su ser, y al ser así autorrevelación con la que comienza y acaba la vida" (Henry, 1996, p. 26). Henry ilustra este saber de la vida a través del ejemplo de un estudiante de biología. Este mueve sus manos para pasar las hojas de un manual en cuyas páginas está contenido el saber de una ciencia particular referido, en este caso, al código genético. Simultáneamente, mueve sus ojos para dar lugar, a través de la identificación de una serie de caracteres impresos, a un proceso complejo de conceptualización que corresponde al saber de su conciencia, realidad mental en la que se asocian una serie de significantes a sus correspondientes significados. Sin embargo, "no es el saber científico el que le permite adquirir el saber científico contenido en el libro; no es gracias a él por lo que mueve sus manos o sus ojos, o concentra su espíritu" (Henry, 1996, p. 27). Efectivamente, el saber abstracto que nos coloca ante el contenido del libro que se encuentra ahí-delante, no es el "saber-mover-las-manos" ni el "saber-mover-los-ojos". En su concreción, estos últimos corresponden al saber de la vida porque no 
son objetivos en sentido alguno, no tienen objeto porque no suponen relación con el objeto. No existe aquí la distancia de la objetividad. ¿Cómo describir, entonces, este saber de la vida que es el del movimiento mismo de las manos que pasan las páginas del libro y el de los ojos que leen? Henry responde:

La capacidad de unirse al poder de las manos y de identificarse con él, de ser lo que él es y hacer lo que él hace, solo la posee un saber que se confunde con ese poder porque no es sino la experiencia que éste hace constantemente de sí; porque no es sino su subjetividad radical (...) un saber que no ve nada y para el que no hay nada que ver, que consiste, al contrario, en la subjetividad inmanente de su pura experiencia de sí y en el pathos de esta experiencia: este es el saber de la vida (Henry, 1996, pp. 27-28).

Esta fidelidad a la realidad inmanente de la vida permite tomar distancia respecto de algunas de las definiciones del ser humano propuestas por el humanismo moderno para pasar, de esta manera, de la dualidad epistemológica humanista a la unidad ontológica de lo humano. Henry se distancia de la idea según la cual el ser humano se distingue debido al pensamiento, ya que al postular que el poder de la conciencia radica en representarse una cosa como esto o aquello, se asume la dualidad en virtud de la cual al representarme algo, estamos ante la cosa puesta delante de mí y mi mirada: el objeto se muestra a partir de las propiedades con las que él aparece en el mundo según mi representación. Por su lado, el realismo objetivista de la ciencia y del marxismo mantiene esta dualidad, debido a que el universo material supone necesariamente el poder de la conciencia ante la que los objetos aparecen y sin la cual estos no existirían. Con la pretensión de superarlo, el realismo del objeto repite en el fondo la dualidad del idealismo de la conciencia.

¿Cuál es, entonces, esta realidad irreductible a las representaciones de la conciencia? ¿Cómo describirla sin caer prisioneros de la dicotomía sujeto-objeto de la que dependen tanto la definición idealista del ser humano cuanto aquella que pretende abordarlo desde una realidad objetiva y material? Henry sostiene que "hay que decir con Marx: esta realidad es la realidad de la vida. En su lenguaje: la realidad de la historia es la de los individuos vivientes; la realidad social es una praxis subjetiva" (Henry, 1990, p. 42). El individuo está ya siempre inmerso en la vida, sumergido por ella y en ella: se trata, pues, de volver a la realidad de lo humano en su inmanencia original, en su unidad ontológica, en su coincidencia fundamental con la vida auto-afectiva. Ningún lenguaje exterior "domestica al hombre", porque la realidad de lo humano está ya siempre dada como esta vida subjetiva radical. La determinación 
fundamental y original del ser desde la que se asume lo humano es la subjetividad que se define y se realiza en ella misma, en su inmanencia radical y en su auto-afección, anteriores a la trascendencia que el humanismo busca en el conocimiento de los textos o de la realidad material y social. En consecuencia, abordar lo humano desde el punto de vista ontológico implica reconocer que las representaciones de los mundos letrado, social y técnico-científico, a partir de las cuales los diversos humanismos confieren al ser humano sus rasgos distintivos, tienen como condición de posibilidad un fenómeno más original que la trascendencia: la vida subjetiva absoluta presente a ella misma en el seno de su auto-afección en la inmanencia.

Henry considera que las representaciones del ser humano elaboradas por las ideologías comunista y capitalista, niegan esta inmanencia de la vida al reemplazar los afectos y la fuerza de los individuos reales en su existencia cotidiana por categorías abstractas, tales como la sociedad, el pueblo, la historia, las clases sociales, la técnica, la producción y el consumo. El "universo de la muerte" se impone y excluye todas las manifestaciones inmediatas del "universo de la vida": lo bello, lo bueno, lo sagrado. Se ha olvidado, por ejemplo, que el fundamento del universo económico está en esta realidad de la vida que, además de caracterizarse por la subjetividad, es una fuerza, un poder productivo. Cuando se olvida que la vida es el fundamento de todo proceso real de producción y que, como sostiene Marx, toda actividad humana es ante todo una fuerza subjetiva de trabajo, entonces tiene lugar la alienación: la vida de los individuos reales -fuerza y afecto- es reducida a una proyección conceptual, a un "ser colectivo" incapaz de sentirse a sí mismo, de desear, de sufrir y gozar. Separado de la idea que él ejemplifica imperfectamente, pudiendo incluso ser sacrificado en nombre de esa idea, el individuo es considerado por las realizaciones históricas del humanismo moderno como un ejemplar de la especie, un instrumento al servicio de un proyecto, un número prescindible, un efecto de las leyes científicas, sociales y económicas. En rechazo a este olvido de lo humano en su realidad y en su concreción, Henry afirma que la realidad inmanente de la vida -la estructura misma del ser- tiene:

La forma de una existencia cada vez individual: (...) esta experiencia singular que se vive y se experimenta a ella misma, (...) que siente y que se siente primero a sí mismo, constantemente afectado por sí mismo y por nada más, y que no es nada más: ninguna alteridad, ninguna objetividad que se pueda ver o tocar, sino, por el contrario, lo que ve y toca, que toma y que actúa" (Henry, 1990, p. 33). 
El comunismo y el capitalismo son precisamente, según Henry, el resultado de haber substituido la vida del individuo real por una serie de entidades abstractas dependientes de la dualidad sujeto-objeto. El racionalismo, en virtud del cual la objetividad de la ciencia moderna es la única garantía de la verdad y del ser, conduce a la negación del individuo: esta razón objetiva y sin vida sobre la cual se fundan el humanismo y el post-humanismo no sabe nada del hombre. El orden ontológico del ser -las potencialidades subjetivas de cada individuo viviente- es reemplazado por "la irrealidad de una entidad objetiva, trascendente, extraña por naturaleza a su vida inmanente. La inversión teórica explica inmediatamente, en los regímenes que ella determina, las perversiones prácticas" (Dufour-Kowalska, 1996, p. 146). En las antípodas del "universo de la muerte" comunista y capitalista, el filósofo reivindica la vida de los afectos y de la fuerza que confieren realidad humana a cada una de las acciones y creaciones del individuo. Como se señaló antes, este individuo real:

(...) no es únicamente el índice de un valor posible, y en consecuencia contingente y variable, sino el origen absoluto de todo valor, porque el individuo encierra la plenitud de la realidad en la inmanencia de su ser, es decir, en esta vida subjetiva de naturaleza afectiva que lo constituye y lo distingue de una piedra o de un robot. [El individuo es] este ser esencialmente subjetivo y afectivo, que marca con un índice de sufrimiento y de dicha todo lo que hace y todo lo que piensa (Henry, 1990, p. 144).

Lejos de la autosuficiencia del homo faber, Henry recuerda que el individuo creador de la economía, y de la cultura en general, no se ha creado a sí mismo. En la medida en que se ha recibido de la vida ya siempre a sí mismo, él es pasivo respecto de su propio ser. Esta pasividad que funda toda posibilidad de acción y de creación cultural marca la esencia original de la realidad inmanente de lo humano:

Es justamente esta pasividad radical del individuo respecto de sí mismo lo que hace de él un viviente. Porque la vida consiste en experimentarse uno mismo de manera tal que esta experiencia es insuperable, que nadie tiene el poder de escapar de ella, de deshacerse de su vida, de ponerla o tenerla a distancia de la manera que fuere. Como viviente (...), el individuo es puesto en la situación que es la suya, la de no haberse creado sino encontrarse a sí mismo, estar siempre de alguna manera ya allí para sí mismo, como si su propio ser lo precediera de cierta manera, como si él fuese segundo no, sin duda, en relación con lo que él quiere cada vez sino respecto del brote primitivo e ininterrumpido de la vida en él. Ser un viviente es ser esto: es nacer de la 
vida, ser llevado, engendrado por ella, de manera que este nacimiento y este engendramiento no cesan, que el individuo solo es la experiencia de este engendramiento interior ininterrumpido que resuena a través de él sin que él lo haya querido y con el que, sin embargo, él se confunde (Henry, 1990, p. 34).

\section{Homo loquens: del lenguaje del mundo al lenguaje de la vida}

Aplicado este proyecto fenomenológico a la descripción del lenguaje como rasgo distintivo del homo loquens, ¿es posible distinguir un lenguaje del mundo y un lenguaje de la vida? Si el aparecer es doble -aparecer mediato del mundo como configuración de sentido y distancia, aparecer inmediato de la vida como fuerza y afecto- y la estructura del lenguaje coincide con la del aparecer, entonces el lenguaje está marcado con el sello de esta duplicidad: lenguaje del mundo (o Logos de la trascendencia) y lenguaje de la vida (o Palabra de la vida):

Si (...) la fenomenalidad se fenomenaliza originariamente según un modo de fenomenalización radicalmente diferente al del mundo, a saber la vida misma comprendida en su esencia fenomenológica pura como autorrevelación, entonces debe existir, tributario de este modo de fenomenalización propio de la vida y en la medida que este se opone rasgo por rasgo al aparecer del mundo, un lenguaje distinto al del mundo, distinto a este lenguaje hecho de significados noemáticos ajenos a la realidad de su referente y al que se limita en general el concepto de lenguaje (Henry, 2004a, p. 335).

Como en todo aparecer, en el lenguaje puede operarse el olvido de la vida. Esto ocurre cuando el sentido, asumido como representación o como configuración de significados noemáticos, introduce una distancia respecto de la realidad inmediata e interna del afecto: la falsificación del pathos en la designación de la cosa por medio de la palabra, en la representación de un evento por medio de la combinación de unidades lingüísticas. Cada vez que, en palabras de Henry, el lenguaje es reducido al cristal transparente del tren a través del cual observamos el paisaje, aquel se agota en su función referencial y niega el aparecer de la vida; en este caso, "el lenguaje no existe (...) Este lenguaje no es, de ningún modo, lenguaje de sí mismo, es siempre lenguaje de otra cosa y se borra delante de esta referencia" (Henry, 2004b, p. 322). Por ejemplo, al decir "el ladrido de este perro me molesta", las palabras empleadas y la frase construida con ellas solo valen en tanto remiten al perro real, es decir, en virtud de una referencia externa que hace invisible e incluso inexistente el lenguaje mismo. Esta distancia establecida entre el lenguaje y 
la realidad se produce cuando el primero aparece según el aparecer del mundo: el empleo de signos lingüísticos, y de las reglas necesarias para su combinación, corresponde a la designación de una serie de elementos que participan en un evento cuyo lugar es el mundo exterior al lenguaje. El lenguaje del mundo niega, de esta manera, la experiencia interna que la vida subjetiva tiene de su propia expresión en el instante en el que, expresándose, se siente a sí misma como este viviente específico que habla y narra. El lenguaje del mundo olvida que la experiencia inmanente de la expresión (o Palabra de la vida) precede siempre a la representación trascendente de dicha experiencia.

No obstante, esta aproximación negativa al lenguaje como lenguaje del mundo es superada por el lenguaje de la vida, entendido como expresión inmediata de la fuerza y del afecto que distinguen lo humano. En efecto, el lenguaje de la vida reconduce tanto el lenguaje del cuerpo, como a las lenguas naturales, a la pura experiencia de sí del cuerpo subjetivo originario: en cada percepción, en cada gesto y en cada acto de habla hay, más que signos que designan un contenido objetivo o ideal, una revelación de la vida a sí misma. El lenguaje de la vida habla allí donde ésta no dice nada más que ella misma: la vida que adviene a sí en la pura experiencia de sí.

Este lenguaje de la vida funda el lenguaje del cuerpo. Todo movimiento percibido desde y por el cuerpo orgánico remite, antes que a un significado exterior, al movimiento corporal mismo, al cuerpo subjetivo originario. Este último funda la realidad del primero como movimiento interior de la vida que no cesa de advenir a ella misma, puesto que en cada uno de los movimientos del cuerpo la vida se dice a sí misma. En este sentido, cada gesto del cuerpo es "símbolo primero", pues su poder significativo es experimentado en la inmanencia de la extensión interior que le es propia. El lenguaje de la vida, que hace posible el "lenguaje corporal en su exteriorización", no sale nunca de su interioridad, ya que remite al puro sentirse y experimentarse como cuerpo que lleva en sí lo invisible que es su propia vida. El lenguaje del cuerpo no es tal porque remita a un contenido en el mundo, sino porque reconduce al propio poder de sentir del cuerpo subjetivo, a un cuerpo en posesión de sus poderes, porque expresa algo que no se ve: una Palabra de la vida, lo humano que se experimenta dado a sí mismo.

Asumido así, como lenguaje de la vida, el lenguaje del cuerpo debe ser descrito por un saber distinto al de la ciencia y al de la conciencia, según se vio en el ejemplo del estudiante de biología. El poder del cuerpo que percibe 
es un poder patético, es decir, consentimiento interior a sentirse afectado, a sufrirse en el deseo de experimentarse como subjetividad absoluta. Aquello que nuestro cuerpo percibe "afuera" es ya siempre, en su origen, pura interioridad. Lejos de constituir el término o correlato trascendente de la conciencia intencional, el árbol percibido afecta al cuerpo viviente en la medida en que lo remite a su poder de sentir, al pathos vivido por quien no puede dejar de ser afectado por esta percepción en toda su radicalidad presente, aquí y ahora. El mundo es simbólico debido a que toda percepción de "lo otro" remite a una pura experiencia afectiva del cuerpo originario. Se puede ilustrar este lenguaje del cuerpo como lenguaje de la vida a través de la manera como, en mi percepción de este árbol, dicho árbol significa:

Este árbol lleva en él toda una constelación de significados que tienen su lugar en mi cuerpo orgánico: su verticalidad que remite a una pura experiencia interior (la de mi propia estatura, la de estar de pie en lucha contra el peso de la gravedad), su verde profundo que ofrece una sombra refrescante en verano, su surgimiento de la tierra, sus raíces sólidamente clavadas, su solidez, la rugosidad de su corteza, la unidad en la que aparece ante mí, experiencias interiores que tienen lugar en la vida inmanente (Vidalin, 2006, p. 62).

En cuanto a las lenguas naturales, hay en el hablar y el escuchar una revelación de la vida a sí misma, en la medida en que el hablante se experimenta y se siente como el hablante que es: no hay separación entre él mismo y su hablar. Las palabras presuponen esta subjetividad que desea poder-sentirse-hablar-y-escuchar: revelación originaria en la que no hay signos, pero que funda y hace resonar toda expresión verbal. La lectura de la teoría de Maine de Biran acerca del doble empleo de los signos, desarrollada por el joven Henry, permite describir, por ejemplo, cómo la palabra "ver" constituye un signo de la experiencia de la visión, que ella expresa en el lenguaje solo en tanto dicha palabra remite a lo que llamamos su interioridad o su profundidad, a saber, la manera como este signo lingüístico coincide con la experiencia interna de la visión: la manera como "el lenguaje está fundado en la vida de la subjetividad absoluta que él expresa" (Henry, 1965, pp. 153-155). Pero no solo el lenguaje natural que expresa inmediatamente la vida de la subjetividad remite incesantemente a esta última. Lo propio ocurre con las operaciones en apariencia mediatas del lenguaje de la reflexión. En efecto, puesto que la representación de la visión como correlato intencional de la reflexión que yo dirijo sobre ella cuando digo "yo veo", ya no es "la visión que ve", esta expresión verbal "presupone la visión real como su fundamento" (Henry, 1965, 
pp. 153-155); en otras palabras, antes de erigirse en designación de la visión en la esfera del ser trascendente, la frase "yo veo" remite a la interioridad del pronombre y del verbo en cuestión, que son el experimentarse inmanente e invisible del ver en su inmediatez patética. Antes de dar cuenta del saber de la conciencia, la construcción verbal "yo veo" coincide con la unidad del saber primitivo del ver como experiencia interna del ser subjetivo del cuerpo, como lenguaje de la vida:

Suponiendo que las palabras "yo veo" designen la representación de mi visión y no mi visión misma, es sobre ésta, sin embargo, sobre su experiencia radicalmente inmanente y sobre ella sola, que reposa en última instancia su significación (...). En el seno de esta vida sensible y motriz que se conoce originariamente a sí misma, y no en la representación de nuestros órganos o de sus propiedades, los signos a través de los cuales expresamos sus diversas modalidades encuentran contenido y sentido (Henry, 1965, pp. 153-155).

Las expresiones verbales entran en posesión de ellas mismas bajo las diversas tonalidades afectivas del cuerpo que se experimenta como cuerpo-que-habla-y-escucha. Las palabras entran en posesión de la realidad de su significado cuando no olvidan su condición de pura experiencia afectiva, del mismo modo como "un color, por ejemplo, una sensación de color, es siempre experimentada y se experimenta ella misma al mismo tiempo que es vista" (Dufour-Kowalska, 1996, p. 189). La encarnación de la palabra en la voz, tal como es simbolizada por la fonación emitida por las cuerdas vocales y transmitida por la garganta y la boca, da testimonio de esta realidad de las lenguas naturales en su experiencia inmanente interior. En esta remisión incesante de cada palabra al saber interior de la vida (sentirse-escuchar-y-hablar), la intencionalidad lingüística se experimenta como poder del cuerpo viviente en el que la vida quiere significarse a ella misma. Una expresión verbal:

(...) solo puede alcanzar tal o tal significado si ya está en posesión, no solamente de ella misma (auto-afección de la trascendencia), sino de la realidad de este significado como pura experiencia afectiva del cuerpo orgánico. Designar el árbol con la palabra "árbol" es posible únicamente porque estoy en posesión de él a través de esta memoria de mi cuerpo que lleva en ella todas las experiencias de mi vida por las cuales estuve presente ante un árbol al estar presente ante mí mismo. Esta es la razón por la cual esta designación es posible, incluso en la ausencia del árbol (Vidalin, 2006, p. 65).

Todo lo que significa en la percepción y en las lenguas naturales remite a aquello que no se manifiesta; a lo invisible. O, como afirma Henry, "se puede 
extender la demostración al mundo que también está hecho de formas y de colores, y mostrar que en el fondo la revelación es doble: todo lo que se muestra fuera de mí [lenguaje del mundo] se revela conjuntamente como un desarrollo de la vida en mí [lenguaje de la vida]. El universo tiene, entonces, su realidad en nuestra vida en tanto esta es dinámica y patética" (Henry, 2007, p. 110). Puesto que el Logos de la trascendencia es ante todo 'Palabra de la vida', podemos estar presentes ante las cosas y ante las palabras tal como nos son dadas porque estamos ya siempre, originariamente, presentes ante nosotros mismos.

\section{Homo narrans: del conocimiento del texto a la exposición patética al relato}

La concepción de la humanitas propia del antropocentrismo renacentista, reafirmada por el pensamiento moderno, se tradujo en el campo de la aproximación a los textos, en los proyectos estrictamente filológicos orientados a conocer la intención original del autor en el marco de un horizonte histórico preciso. En su intención de conocer el texto a partir de este método, en lugar de dejarse abordar por él, el lector-filólogo coincide con el lector-estructuralista. Allí donde el primero funda su erudición en el develamiento de la verdad sobre el origen de los escritos, el segundo hace suyos los esfuerzos de la narratología por constituir una verdadera ciencia del relato basada en la distinción entre el aspecto interno y ficcional del texto, por un lado, y la dimensión externa y real del mismo, por otro lado. Solo si se mantiene dentro de las fronteras del texto, el estudioso de la literatura será capaz de emprender la reconstrucción racional de las reglas subyacentes a la actividad narrativa.

Sin desconocer los aportes de estas dos empresas -filología y narratología-al estudio de la configuración del relato, ellas resultan insuficientes para quien quiere escuchar "el Decir" de una palabra viva nunca ofrecida al conocimiento definido de "lo dicho", nunca reducida a su pretendida adecuación a las expectativas de un método preciso; en otras palabras, para quien rechaza el "irracionalismo de la comprensión inmediata", así como el "racionalismo de la explicación que extendería al texto el análisis estructural de los sistemas de signos" (Mongin, 1994, p. 135). Por ello, la hermenéutica en tanto fenomenología de la experiencia literaria tal como la vive el lector, se asume a sí misma como la descripción de una "inteligencia narrativa siempre previa" y, por ello, crítica respecto de "la decisión metodológica, propia del análisis estructural, de tratar a la literatura con las categorías lingüísticas que imponen la distinción entre lo 
interno y lo externo", oposición contraria a "aquello que hemos comprendido, cuando niños, como una historia” (Ricoeur, 2009, p. 49).

La hermenéutica ha llevado a cabo un desplazamiento del lector-filólogo-estructuralista hacia el lector-pastor-del-ser heideggeriano, el lector-interlocutor levinasiano y el receptor-vivo de Ricœur. Aunque cada uno de estos lectores merecería un desarrollo detenido, baste resaltar, para los fines de este artículo, que los tres son confrontados a los textos en su exterioridad y en su alteridad: los tres se abren a propuestas de sentido que los preceden, que no provienen de ellos mismos y que, por ello, no agotan su densidad en los métodos del científico de la literatura. En el caso de Heidegger, este movimiento de exposición a "lo otro" remite al horizonte del ser cuya casa es la poesía. En el pensamiento del joven Levinas, dicho movimiento implica dejarse interpelar por los textos del pasado como quien escucha el llamado de un interlocutor, con todo el vigor de la oralidad y del diálogo entre maestro y discípulo, para descubrir la expresión (el poder decir de una palabra-viva) que supera la intención (el querer decir de las palabras-signo o las palabras-imagen fijadas por la escritura) (Levinas, 2011). En la obra de Ricœur, esta salida de uno mismo se realiza al acoger las narraciones recibidas de la cultura que nos precede, cuyas intrigas coinciden con nuestra temporalidad humana y hacen posible la conformación de nuestra identidad narrativa. Estas tres formas de alteridad narrativa fundan, respectivamente, la proyección de un mundo, la responsabilidad frente al rostro del Otro y la identidad de un cogito herido y capaz.

Como es evidente, esta alteridad narrativa exige mantener una dualidad que pretende integrar lo interno y lo externo. Desde esta dualidad define Ricœur el espacio de intersección en el que se ubica la hermenéutica, a saber, el punto de unión entre la configuración (interna) del sentido en el relato y la refiguración (externa) de la vida por medio del relato: la posibilidad de "hacer cercano lo lejano" al interpretar (Ricoeur, 1983). Pero ¿cómo describir este modo de lo imaginario en cuyo seno la historia narrada en estructuras lingüísticas precisas, y desde una estructuración ficcional de la intriga, es al mismo tiempo -no en dos tiempos- vivida? ¿Cuál es, fenomenológicamente, el fondo de unidad y de simultaneidad primeras sobre el cual resuenan a la vez lo narrado y lo vivido, lo ficticio y lo real, antes de cualquier distinción entre el antes y el después del texto; antes de que el mundo vivido $u$ horizonte del lector se comprenda una vez levantado ante él el horizonte o mundo del texto; con anterioridad, entonces, a la separación entre el ser humano y el mundo, entre 
el ser humano y los otros seres humanos, entre el ser humano y él mismo, instancias cuya mutua comprensión está garantizada, según Ricœur, por toda mediación anamnética ficcional que tenga como sujeto narrativo a uno cuya historia desea efectuarse según el modo de la referencialidad no descriptiva, la comunicabilidad no utilitaria y la reflexividad no narcisista? (Ricoeur, 2009, pp. 49-50).

Si intentamos responder a estas preguntas a la luz de la fenomenología henriana del lenguaje, expuesta en el apartado anterior, podemos sostener que las narraciones a las que el viviente humano es expuesto, resuenan en el ámbito inmanente de la auto-afección del que provienen: ellas son, antes que una refiguración de la acción en el mundo, lenguaje de la vida. Este nivel de interioridad auto-afectiva, de inmediatez patética, es, precisamente, el "fondo de unidad primera" al que aluden las preguntas formuladas en el párrafo anterior. Se trata de la realidad inmanente de lo humano en su poder de auto-afección: el pathos fundamental al que los relatos remiten, y en el que lo humano se experimenta y se acrecienta sin cesar.

Puesto que esta realidad inmanente de lo humano funda toda experiencia, sin ser ella misma fundada, los relatos inscritos en la cultura de la vida subjetiva radical exceden el régimen del significado y, con él, las representaciones del ser humano elaboradas por el humanismo clásico, el humanismo moderno y el post-humanismo. Se pueden señalar tres consecuencias importantes de esta aproximación henriana al homo narrans en el marco de una cultura de la vida auto-afectiva:

a) Antes de cumplir el rol de mediación simbólica, antes de ser interpretados en el marco del universo simbólico de una cultura, los relatos son elaborados y transformados por el deseo de la vida subjetiva de experimentarse y de sentirse a sí misma en el seno de las narraciones a las que es expuesta. Los relatos son, en este sentido, lo que la vida elabora y transforma (la vida como sujeto del narrar humano). Pero, en el deseo de significarse a sí misma, la vida resulta ser también lo que es elaborado y transformado por los relatos (la vida como objeto del narrar humano). El saber de la vida que hace posible toda creación narrativa y que, simultáneamente, es repotenciado por ésta, es el saber de la cultura: "Toda cultura es una cultura de la vida, en el doble sentido en que la vida constituye a la vez el sujeto de esta cultura y su objeto. Es una acción que la vida ejerce sobre sí misma y por la que se transforma a sí misma en cuanto que es ella misma la que transforma y lo que es transformado" (Henry, 1987, p. 19). 
b) Sobre el fondo de la auto-afección, cada exposición a los relatos confronta al viviente a un debate interno que coincide con la dinámica misma de la vida. En efecto, la exposición a los relatos del pasado coincide con el deseo de la vida de auto-afectarse en esta adhesión primera e inevitable a sí misma, en este no poder distanciarse ni escapar de sí - pathos del sufrimiento-, que se transforma de inmediato en la alegría de sentirse aún más, de modificarse y recrearse a través de nuevas experiencias de escritura y de lectura-pathos del gozo de la creación y de la recepción literarias. En virtud de este debate afectivo interno, la vida subjetiva consiente a dejarse afectar por las imágenes y el ritmo de los relatos, los cuales constituyen descargas creativas del pathos de la vida. Como toda expresión de la cultura, los relatos expresan el pathos cargado de sí mismo -instante del sufrimiento- y abren, a la vez, a un movimiento igualmente patético de catarsis - momento de la exaltación, de la ebriedad:

(...) el arte ha tenido por móvil este pathos cargado de sí mismo, que quiere descargarse de su propio peso y que, al no poder hacerlo, se modifica profundamente por la alegría, por la dicha -el arte es un arte de dicha para mí, incluso cuando cuenta cosas atroces (...). Porque la vida es siempre este esfuerzo que atraviesa el sufrimiento, el malestar, para ir hacia una cierta liberación (Henry, 2004b, p. 323).

De esta manera se encuentran ya siempre fusionadas, antes de cualquier distinción entre lo interno y lo externo, la exposición a los relatos y la realidad inmanente de lo humano, cuya fuerza irrumpe de una manera particularmente intensa cuando la vida subjetiva se siente afectada por la intriga de los relatos de ficción -exposición padecida en el "aquí y ahora" de la configuración textual-, pathos del sufrimiento que deviene de inmediato en pathos del gozo, es decir, en deseo de gozar de nuevas variaciones imaginativas, de fuerzas y márgenes de acción inéditos -apertura al "allá" de múltiples refiguraciones y connotaciones.

c) Puesto que coinciden con la realidad auto-afectiva de lo humano, tanto en la violencia y el peso de su adhesión a la vida como en su deseo de acrecentarse en cada nueva expresión cultural, los elementos del relato expresan de manera inmediata el sufrir y el gozar de la vida subjetiva por un fenómeno de co-impresión. En efecto, antes de toda "operación dinámica de puesta en intriga", dichos elementos remiten a aquello que no se manifiesta, a lo invisible. Los relatos dan testimonio de la profundidad de 
lo visible: estas narraciones significan en el horizonte de la exterioridad $\mathrm{y}$, sin embargo, resuenan en nosotros según su tonalidad interior. Y tienen un interior porque la vida de los relatos es esta vibración, este quiebre estremecedor de nuestra vida:

En cuanto a los objetos, solo nos tocan y solo existen en esta resonancia patética, su experiencia es nuestra subjetividad misma. Es cierto que hemos dejado de oír esta resonancia en las cosas más simples. Su uso inmediato, hacia el que nos empuja la existencia ordinaria, ha cubierto con un velo su sonoridad profunda. La función de extrañeza del arte, al superar el significado de utensilio del que los objetos se cargan en los asuntos cotidianos, consiste en devolver a los objetos eso que llamamos su vida: este estremecimiento de la nuestra, este estremecimiento en el que ellos nos advienen (Henry, 2004c, p. 239).

Las palabras explotadas en su fuerza sensorial y afectiva -más allá de la pretendida univocidad de los conceptos- provienen de este deseo de auto-afectarse de la vida como apertura a sensaciones y significados inéditos potenciados por la materialidad misma de los relatos. Esta materialidad es dinámica y patética, ya que su función referencial (exterior al lector) queda subordinada a la impresión de las palabras en el espacio invisible de la subjetividad: "el lugar del arte no tiene nada de objetivo (...) el universo de la pintura [como el de la literatura] no es el de lo visible" sobre todo si "el ser de cada color [como el de cada palabra] no es, en realidad, sino su impresión en nosotros" (Henry, 2004d, p. 284). El despliegue icónico de lo real, operado según Ricœur por la literatura, persigue entonces, antes que la extensión de nuestra visión del mundo, el acrecentarse de "la sensibilidad de las formas, su poder de ser experimentadas por nosotros, la auto-afección constitutiva de todo ser sensible" (Dufour-Kowalska, 1996, pp. 239-240).

Antes de proponernos un mundo en el que podríamos habitar, las representaciones de la praxis humana propuestas por el quehacer narrativo en el marco de los diversos humanismos, nos remiten a la realidad inmanente del pathos de la vida. En lugar de responder a la abstracción de las leyes internas del relato propias de la semiótica narrativa, la interioridad patética de los relatos, fundada en una cultura de la vida auto-afectiva, traduce el arraigo de las narraciones en la vida subjetiva radical: la remisión incesante del cuerpo subjetivo a la realidad inmanente de lo humano en el instante de su exposición al cuerpo viviente de los relatos. 


\section{Conclusión: la educación semántica o la recuperación de lo humano}

A partir de estas pistas de reflexión elaboradas en diálogo con Michel Henry, proponemos revalorar la exposición a los relatos del pasado en el marco de una cultura de la vida y de la educación semántica: el trabajo por el desarrollo humano supone también exponer al viviente a la creatividad lingüística y a la densidad humana de los relatos propios y ajenos. Se trata de asumir, en diversos espacios de formación, la lectura de las narraciones de nuestra y de otras tradiciones culturales en tanto experiencia radical de una subjetividad, es decir, en tanto realidad humana que se siente y se experimenta como la vida que es, gracias a la manera como los elementos del relato son elaborados y transformados por la vida, y son a la vez los agentes de elaboración y de transformación de la vida.

La realidad inmanente de lo humano se desea a sí misma en el "aquí y ahora" de la configuración narrativa y, simultáneamente, es apertura al "allá" de las múltiples connotaciones que la interpretación atenta del relato consigue escuchar. Los relatos que no debemos dejar de transmitir de generación en generación, provienen de este movimiento inmanente de lo humano y permiten a este movimiento proliferar en el lector que es expuesto a dichas narraciones. En efecto, los relatos del pasado exponen al viviente a su propia humanidad, en la medida en que quien lee o escucha se siente afectado por el ritmo y por la densidad existencial del relato que le es ofrecido. Pero este movimiento de auto-afección puede abrirse al rostro del otro ficcional que habita el relato, así como al de aquellos con quienes los textos pueden compartirse y recrearse. Por ello, este pathos radical al que el relato nos enfrenta, se transforma en el deseo de compartir dicho relato con el otro, quien se descubre capaz de recrear esta narración y abrirse, así, a todas las expresiones culturales en las que la realidad inmanente de lo humano se auto-afecta y crece.

En consecuencia, la exposición a los relatos del pasado constituye una respuesta a la barbarie de "lo nunca visto", porque en dicha exposición se integran los valores que el predominio de la técnica tiende a desarticular: la realidad inmanente de lo humano en las manifestaciones de lo bello, lo bueno y lo sagrado. Allí donde se suele reducir la calidad de vida de las personas a su margen de utilidades o a la posesión de determinados recursos, consideramos muy importante afirmar que el despliegue integral de lo humano no incluye únicamente las herramientas técnicas de la ciencia económica -útiles para atacar las causas objetivas de la desigualdad-, sino los recursos 
y procedimientos de la literatura, la memoria histórica y el arte. Estos lenguajes permiten abordar los factores subjetivos, intangibles pero latentes, de dicha desigualdad, a través de nuevas narrativas promotoras de libertad y de cambios culturales profundos. La lectura de relatos motiva la recreación de significados, testimonios y experiencias del pasado para reconfigurarlo todo desde una acción cultural, que no solamente cambie los programas políticos y económicos, sino también los modos de pensar y de sentir.

Desde una motivadora relectura de Marx (Henry, 1976 y 2011), Henry nos advierte de los peligros de una alienación capitalista que podríamos encontrar también en las políticas sociales y de transferencia de recursos que reducen el desarrollo humano a la satisfacción de necesidades, como si dicha satisfacción se diera de manera natural, mecánica, inmediata. Cuando las necesidades son naturalizadas, se desconectan del enigma de la vida del vulnerable y de su deseo de vivir. Olvidamos, entonces, que las necesidades del viviente en relación con su medio de vida y de muerte están marcadas por la injusticia y que, por lo tanto, la satisfacción de dichas necesidades está atravesada, ante todo, por la experiencia subjetiva y afectiva que hace de toda necesidad una necesidad de cultura. Pan y palabra, salud e imagen, abrigo y narración van de la mano porque, en el socialmente vulnerable, las necesidades de alimento, de integridad física y de vestido deben poder ante todo experimentarse en su carga, en su peso, en su pathos radical. En ese sentirse humano en la necesidad, el vulnerable vive ya dicha carencia como necesidad de cultura y de memoria, es decir, como una apertura a la creatividad y a la puesta en relato del deseo vital de comer, de curarse y de abrigarse, que es al mismo tiempo deseo de que otras vidas igualmente particulares puedan gozar de alimento, salud y cobijo: necesidad de cultura porque toda necesidad es, de entrada, elaborada humanamente y deseosa de tomar posesión de la necesidad que ella es, de narrarse, de reconocerse, de ser afectada, de experimentarse en el consentimiento violento de su propio peso y en la apertura a compartirse con otros.

Este es el sentido primero del rostro del vulnerable que brota de la exposición a los relatos de su propia fragilidad, a saber, su poder y su deseo de experimentarse, de auto-afectarse, de adherirse con violencia y dolor a la vida golpeada que él es, para encontrar en el seno mismo de esta adhesión sufriente la alegría de gustar y sentir, de ser vivo en tanto vulnerable. Solo entonces, habiéndose recibido a sí mismo con todo el peso del "aquí" y el "ahora" -la 
vida que él es y que no puede dejar de ser-, el socialmente vulnerable puede abrirse al "allá" de sus capacidades para hacer frente a dicha vulnerabilidad -la vida en la que él adviene como desborde y como creación.

Por ello, frente a los modelos educativos que ponen el acento en el rendimiento calculable y en la competencia, debemos asumir la exposición a los relatos como una fuente de responsabilidad frente a los socialmente vulnerables, a partir de un gozar de la literatura y el arte que se transforma de inmediato en sufrir 'por y con' el hambre del otro, así como en la alegría del servicio concreto al que dicho sufrimiento nos consagra. La donación de los relatos recibidos del pasado está fundada, pues, en el sufrir 'por y con' el no reconocimiento de los vulnerables y en la alegría de saberse escogido para responder desde una concepción integral del desarrollo fiel a la realidad inmanente y auto-afectiva de lo humano. Los procesos educativos en los que el socialmente vulnerable no se limita al rol de consumidor pasivo, sino que asume la exposición a los relatos como una actividad creativa, liberadora y transformadora de su propia situación, juegan un papel fundamental en la constitución de nuevas narrativas y mentalidades generadoras de cohesión social. El instante en el cual la creación y la escucha de los relatos golpean nuestras conciencias y revelan los significados abiertos por quienes son considerados como insignificantes en una sociedad es un instante a la vez ético y estético: un camino fundamental para responder al otro socialmente vulnerable y contribuir responsablemente con la educación de los hombres y mujeres de nuestro continente.

\section{Referencias}

Dufour-Kowalska, G. (1996). L'art et la sensibilité. De Kant à Michel Henry. Paris: Vrin.

Henry, M. (1963). L'essence de la manifestation. Paris: Presses Universitaires de France.

Henry, M. (1965). Philosophie et phénoménologie du corps. Essais sur l'ontologie biranienne. Paris: Presses Universitaires de France.

Henry, M. (1987). La barbarie. Paris: Presses Universitaires de France.

Henry, M. (1990). Du communisme au capitalisme. Théorie d'une catastrophe. Lausanne: Éditions L'Âge d'Homme. 
Henry, M. (1996). La barbarie. (Trad. Domingo Moratalla, T). Madrid: Caparrós.

Henry, M. (2004a). Phénoménologie matérielle et langage (ou pathos et langage). hénoménologie de la vie (Tome III). De l'art et du politique. Paris: Presses Universitaires de France.

Henry, M. (2004b). Narrer le pathos. Phénoménologie de la vie (Tome III). De l'art et du politique. Paris: Presses Universitaires de France.

Henry, M. (2004c). La peinture abstraite et le cosmos (Kandinsky). Phénoménologie de la vie (Tome III). De l'art et du politique. Paris: Presses Universitaires de France.

Henry, M. (2004d). Art et phénoménologie de la vie. Phénoménologie de la vie (Tome III). De l'art et du politique. Paris: Presses Universitaires de France.

Henry, M. (2007). Entretiens. Arles: Sulliver.

Henry, M. (2011). Marx (Tome I). Une philosophie de la réalité. Paris: Gallimard, 1976. En castellano Marx (Tomo I). Una filosofía de la realidad. (Trad. Gómez, N). Buenos Aires: La Cebra.

Leclercq, J. (2010). Biographie de Michel Henry. Leclercq, J (Ed.). Pour une phénoménologie de la vie. Entretien avec Olivier Salazar-Ferrer. Mayenne: Éditions de Corlevour.

Levinas, E. (2011.) Euvres 2. Parole et silence et autres conférences inédites. Paris: Éditions Grasset et Fasquelle.

Mongin, O. (1994). Paul Ricœur. Paris: Éditions du Seuil.

Ricoeur, P. (1983). Temps et récit (Tome I). Paris: Éditions du Seuil.

Ricoeur, P. (2009). La vida: un relato en busca de narrador. Educación y politica. De la historia personal a la comunión de libertades. Buenos Aires: Prometeo.

Sloterdijk, P. (2000). Règles pour le parc humain. Paris: Éditions Mille et Une Nuits.

Vidalin, A. (2006). La Parole de la Vie. Paris: Éditions Parole et Silence. 